Online Library Systems for Malaysian School Libraries: An Experimental Approach

\title{
Online Library Systems for Malaysian School Libraries: An Experimental Approach
}

\author{
Zainab A.N and Abrizah Abdullah \\ Department of Information \& Library Science, \\ Faculty of Computer Science \& Information Technology, \\ University of Malaya, \\ 50603 Kuala Lumpur \\ Malaysia \\ zainab@fsktm.um.edu.my,abrizah@fsktm.um.edu.my
}

\begin{abstract}
This paper describes the development of two experimental school library information systems for Malaysian schools. The results of a user study, conducted using different sets of questionnaire for both types of schools indicated that students in general, borrowed books from the library by browsing the shelves. Students seldom used the catalogue card for searching and only a small percentage reported that they were able to find the books successfully using the catalogue card. Based on the findings, a conceptual model of the prototype automated catalogue was developed - Virtual Library for use in primary schools, and ELIS for secondary schools. Both systems are divided into two main modules, the Administrator and the User module. User acceptance test showed that the majority of students found the systems user friendly. Students were also successful in the search tasks given. A high majority described the graphical user interface to be attractive and simple. This indicates the feasibility of using the systems for school libraries in Malaysia.
\end{abstract}

\section{Introduction}

Schools worldwide have been adopting computers for classroom instruction since the early seventies, however little research has been done to address the questions of how to automate school libraries for students in ways concordant with their learning, cognitive development and curriculum. This leads to the need to understand more about children's information seeking abilities in order to design information retrieval systems that could be used effectively and enjoyably by children from a wide range of background, without prior computer experience and without any training in the use of the system (Borgman, et.al. 1995).

Professional literature and texts on children's online information seeking behaviour indicated that they lack retrieval skills. Students tend to have minimal typing skills (Drumm \& Groom, 1999), and they typically "hunt and peck" on the keyboard for the correct keys when they issue a search (Borgman, 1995). Hooten (1989) identified accuracy in spelling, spacing and punctuation as a significant problem in primary school children. Siegler (1991) stated that children are often confused with the workings of Boolean logic. Other skills that most children lack include the ability to extensively browse alphabetical displays which is age-related, with older children performing better (Edmonds, Moore \& Balcom, 1990) and inadequate subject vocabulary, that is children may not be articulate with the subjects used by 
the catalogue, making it difficult for them to use appropriate terminology to match the index terms used for the catalogue (Moore \& St. George, 1991). These factors have shown that the current available online catalogues did not meet children's need, ignoring their cognitive developmental level.

One factor that could alleviate some of the user difficulties with current online retrieval system is the manner of interaction between the users and the systems. The primary requirement is the visual element. (Borgman et.al. 1995). Text output with visual objects on the computer screen better describes the result of operation and enable users to be competent in performing their tasks (Al-Hawamdeh, 1995). Clements (1995) identified that an ideal information retrieval systems for school children should often involve 'hitting a single key or any key as responding to icons representing subjects on the screen' and have menus and help at all level of searching. In order to ascertain that these features can be applied within local context, catalogue use and book searching behaviour of students was carried out prior to the development of an experimental library system for use in Malaysian schools.

\section{Objectives}

The objectives of this paper are threefold. Firstly to describe the findings of a survey which sought to find out students' computer skills and how they searched for books borrowed from the school library. Secondly to describe the prototype developed as an automated catalogue for the school library. Thirdly, to describe the students' responses when using the automated systems.

\section{The Survey}

Two surveys using different sets of questionnaire for both primary and secondary schools were conducted. The first survey conducted at three primary schools in Kuala Lumpur, used a sample of 30 students and was carried out over a period of three days. Subjects comprised children in the 8 to 12 year-old age range with a more or less equal divisions of girls and boys. They were ethnically and culturally diversed. The second survey involved 40 samples, consisted students from Form 1 - Form 6. The first school (18 students) is currently using an automated library system, whereas 22 respondents from the second school reported that they have not used online catalogue before since their school library is not automated. Samples were selected from classes visiting the school library at the point of the visit.

Both surveys used the questionnaire method to obtain the information needed. Three questions were of particular interest in this survey:

a) What is the students' frequency of library use, computer skills and knowledge of online searching?

b) How do students search for books in the library?

c) What are the design considerations in constructing an interface for both primary and secondary school students?

Both questionnaires, although differently constructed, have two parts. Part A aimed at finding out respondents' background, frequency of library use, library skills, computer skills and knowledge of online searching. Part B aimed to find out the searching skills of respondents in finding library books through the available card catalogue system, and their views of the system. 


\section{Results}

\section{Part $A$ of the Questionnaire}

Primary schools

a) Frequency of library use - The majority of students $(76.7 \%, 23)$ visit the library more than once a week; $16.7 \%$ (5) visit the library once a week and only 2 students $(6.6 \%)$ visit the library once a month.

b) Reasons for visits - Seventeen (56.7\%) visit the library because they were taken there by their teachers, $10(33.3 \%)$ went to the library to read storybooks and $3(10 \%)$ reported visiting the library to borrow books.

c) Means of finding books - About $93 \%$ (28) obtained books by browsing the shelves, while only a small percentage asks the teacher-librarian for help to search for books.

d) Success in finding books - About $87 \%$ (26) reported getting the books they want, and only $13 \%$ (4) reported otherwise.

e) Types of problems faced when finding books - all reported "books are not on the shelves".

f) Language Fluency - A high majority $(96.7 \%, 29)$ are fluent in both Bahasa Malaysia and English Language.

g) Computer Usage - all students have experiences in using computers.

h) Keyboarding skills $-56.7 \%$ (17) reported that the keyboard is difficult and confusing to use. However the majority $(93.3 \%, 28)$ indicated that they were more familiar with mouse use.

i) Knowledge of keyword search - all students did not know about keyword search.

j) Knowledge of Boolean operators - results indicated that Boolean operators are foreign to the students.

Secondary schools

a) Frequency of library use $-40 \%$ (16) visit the library more than once a week; $50 \%$ (20) visit the library once a week and only 4 students (10\%) seldom visit the library.

b) Reasons for visits - 65\% (26) use the library to obtain references; $15 \%$ (6) go to the library to do their homework; $15 \%$ (6) reported visiting the library to read storybooks; while 5\% (2) indicated "follow friends" as reason for visits.

c) Means of finding books - 40\% (16) obtained books borrowed by using the catalogue card. Others normally browse the shelves.

d) Success in finding books - More than 75\% reported not getting the books they wanted.

e) Types of problems faced when finding books - Books on the shelves in disarray constitute the main reason for search failure.

f) Language Fluency - Respondents seems to be more fluent in Bahasa Malaysia $(70 \%, 28)$ than in English.

g) Computer Usage - All respondents are computer literate.

h) Keyboarding skills - All respondents know how to use computer keyboards.

i) Knowledge of keyword search - Half of the respondents indicated that they did not know what keyword search means.

j) Knowledge of Boolean operators - Only 2 students indicated that they knew about Boolean operators.

\section{Part B of the Questionnaire \\ Primary schools}

This section aimed to find out the searching skills of respondents in finding library books through the available card catalogue system. All respondents $(66.7 \%, 20)$ from the first 
and the second school have had the experience using the catalogue card. The respondents from the third school reported not having explored the catalogue card before since it is not available in the school library. The frequency of using the catalogue card is quite low $-50 \%$ (15) of the children are not using it, 30\% (9) reported seldom use it, $13.3 \%$ (4) chose sometimes, and only $10 \%(6.7)$ replied always. The survey found that "Title" is the most popular catalogue approach $(56.7 \%, 17)$, followed by author $(30 \%, 9)$ and subject $(13.3 \%, 4)$.

To understand the mental search strategy used by the primary school students when searching by 'Author', they were asked to indicate their selection of author's name. The majority of the students chose the direct form of name - 96.7\% (29) used 'Osman Bakar' (only one child chose Bakar, Osman or Bakar) and 86.7\% (26) used 'Arthur Clarke' (the rest chose "Clarke, Arthur" or "Arthur" or Clarke"). Students were also asked on the appropriate search approach and search terms that they would use to search for any books. Results indicated that most children were able to use the author catalogue approach, (e.g. all books written by Enid Blyton) however they were confused in whether to use the title or the subject catalogue approach (e.g. "all books about Gunung Ledang" and "all books about mountains").

According to the 12 children who have had the experience using an online catalogue, $75 \%$ (9) found that it is easy to use, $16.7 \%$ (2) quite easy and $8.3 \%$ (1) replied quite difficult. The majority of them prefer using the online catalogue to the catalogue card system with the reason that searching online is faster and easier. Finally, the features that the children would like to see in an online catalogue, ranked in order, are "searching without typing required", "display library news and announcements" and " attractive and colourful graphical user interface".

\section{Secondary schools}

This section sought to find out the potential of using an automated system; the features and the design consideration in constructing an interface for the system. All 18 students from the school that is currently using an automated library system indicated that searching for books by typing the search criteria is not difficult. Sixteen students prefer finding by subject, followed by keywords, title and author, while the remaining two would search by title, followed by subject, keywords and author. All of them indicated that they prefer using the automated system to the catalogue card. When asked to list the features that they would like to see in the current system, some of the responses were "book availability", library announcements, school/library events, and use of icons and buttons, mailing and printing capabilities.

All respondents (22) from the second school reported having used the catalogue card to search for books if the titles or authors are known. However the frequency of using the catalogue card is quite low $-80 \%$ of the respondents are not using it frequently. They prefer browsing the shelves and indicated that they find the books by remembering their location on shelves. If given a choice, all respondents said that they would like to search for books using an automated system.

\section{Implications}

a) Younger children are more oriented toward browsing and find the mouse to be exceptionally easier to use than keyboard. Various browse types of search methods should be presented in an online catalogue. 
b) Cataloguing practice adopted by most libraries to invert Western names is perhaps "incomprehensible" to Malaysian children. Therefore catalogues for children must allow for access to author's name in its direct order, as this is the 'natural' way young children search for this information. For those who are used to the 'standard' way, access should be given to the second element of the name.

c) Access through the title need to be enhanced so that children can either search for the title as whole or each word in the title.

d) Access through the subject mode need to be enhanced allowing search of every word in the subject field.

e) Older children may be more adept at keyword searching. Therefore an expert mode of searching should be incorporated, allowing the experienced users to refine searches with Boolean Operators.

f) Design of the system and its interface should be user friendly, easily understood by all level of users, consistent, simple and attractive.

Based on the findings from the two surveys, a conceptual model of the prototype automated catalogue, Virtual Library and ELIS was developed (Figure 1). The model indicates that both systems are divided into two main modules - the Administrator's module and the User's module

Figure 1: Conceptual Diagram of Virtual Library \& ELIS

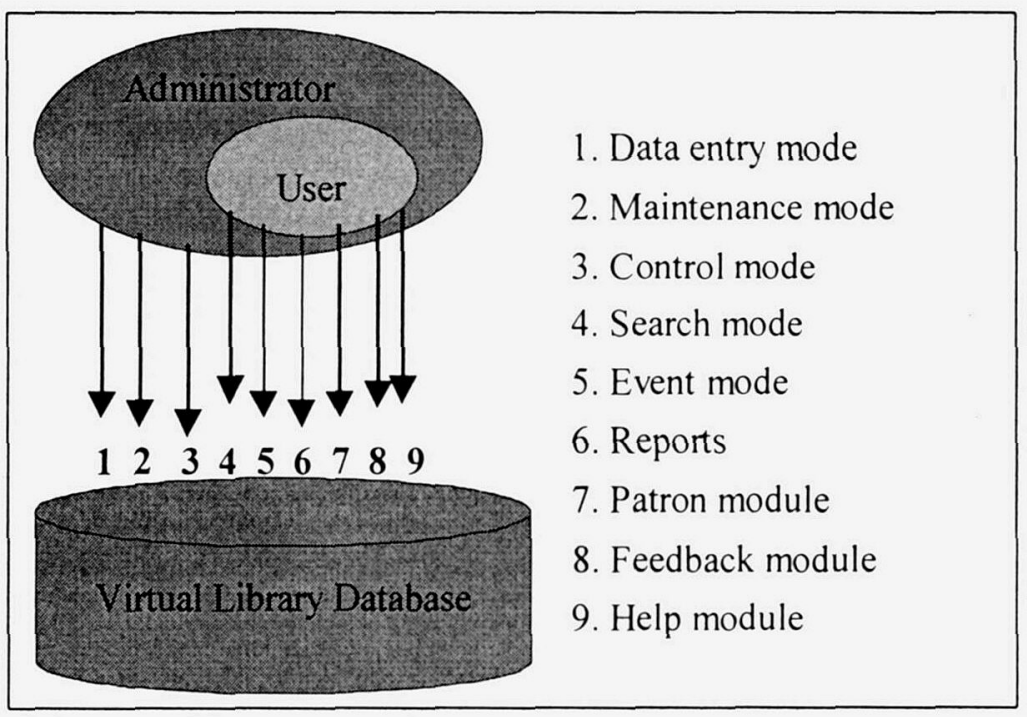

\section{Virtual Library - A Graphical Online Library System for Primary Schools}

The Administrator's module allows teacher librarians to perform the following basic functions: a) to enter, amend and delete item or patron records and library events, b) to update, backup and compact the database, c) to print records entered. Access into the Administrator's module requires a password. The User's module allows users to a) search for library items, b) view library events and announcements, c) send comments or suggestions to teacher librarians. Virtual Library keeps all relevant data in a Microsoft Access database. The database is then linked to Visual Basic 6.0 applications to perform functions such as editing and adding records via designed worksheets and menus. Figure 2 and 3 describes the provisions given under the Administrator and User Module. 
Figure 2: The Administrator's Functions Structure Chart
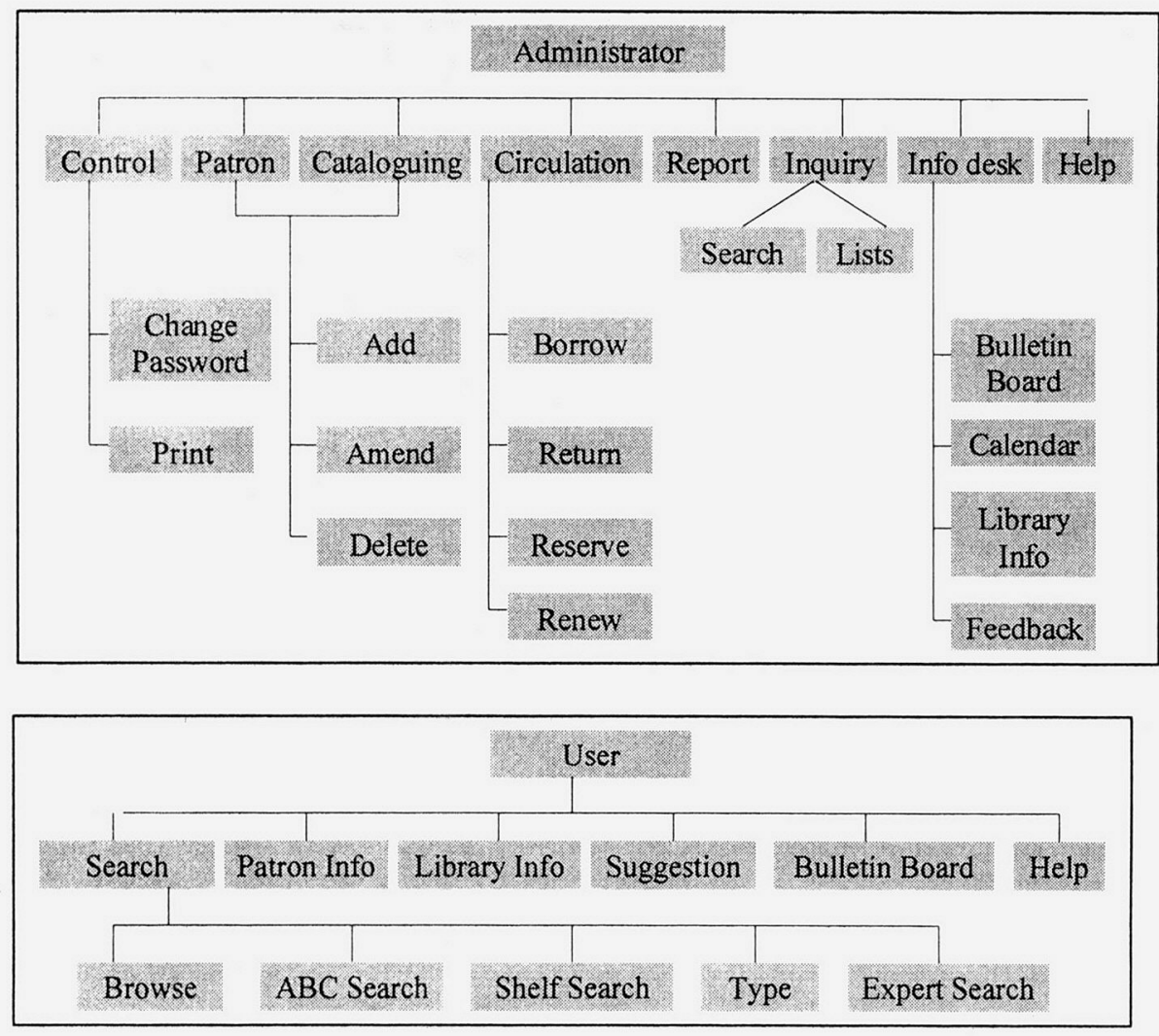

Figures 5 and 6 presents the main screen for both modules with the options provided in the main menu.

Figure 5: Administrator Main Screen of Virtual Library

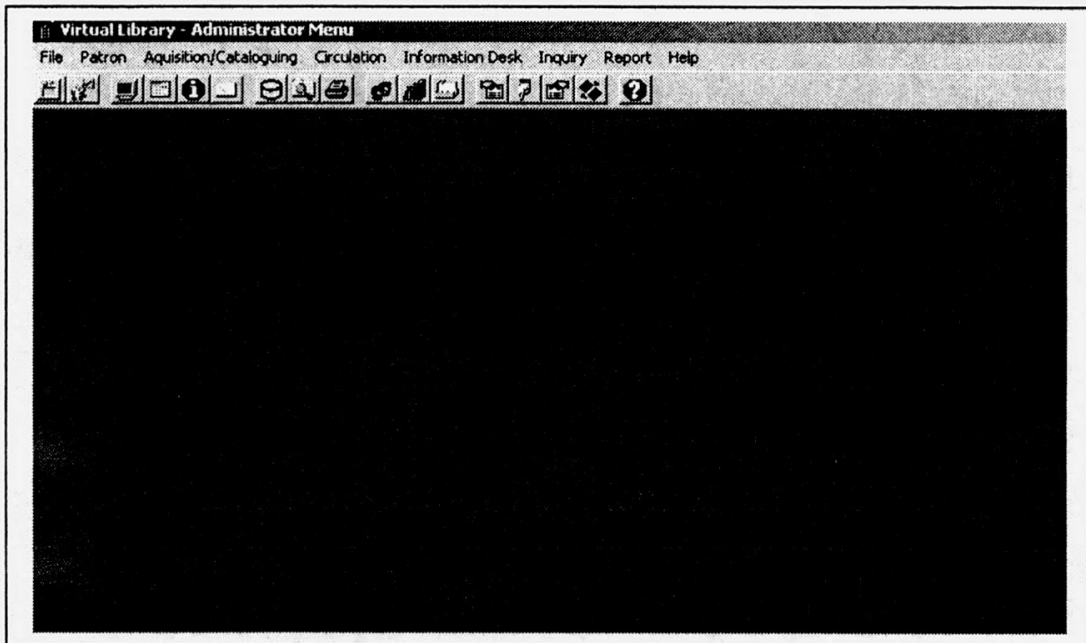


Figure 6: User Main Screen of Virtual Library

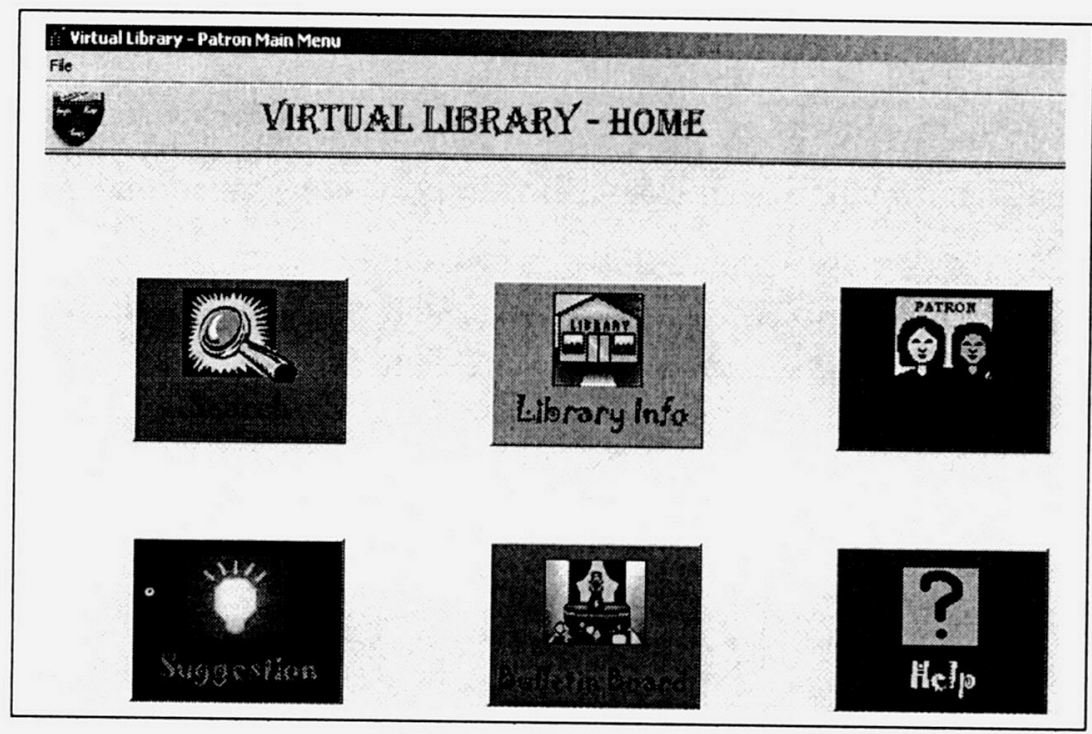

Virtual Library provides five methods to search the library's catalogue - ABC search, browse, shelf search, type search and expert search. ABC search, browse and shelf search are designed for children who are not adept at keyboarding skills, or at conceptualizing searchers. The point and click interfaces guide the children in their searches. ABC search lets children find information on authors, titles or subjects of their interests by alphabets. Children only need to identify the first letter their topic begins with, then browse the buttons provided. This type of interface is very productive for children who have word recognition capabilities. Browse allows children to browse the catalogue by subjects. The shelf search allows children to review library items shelved on either side of a call number, just as if they were standing in front of a bookshelf and browsing at the stacks. Type search is for children who have keyboarding skills. An expert mode of searching is also incorporated, allowing the older children to refine searches with OR and AND Boolean operators. Figure 7 presents the search screen with different searching modes for different levels of users.

Figure 7: Virtual Library Search's Screen

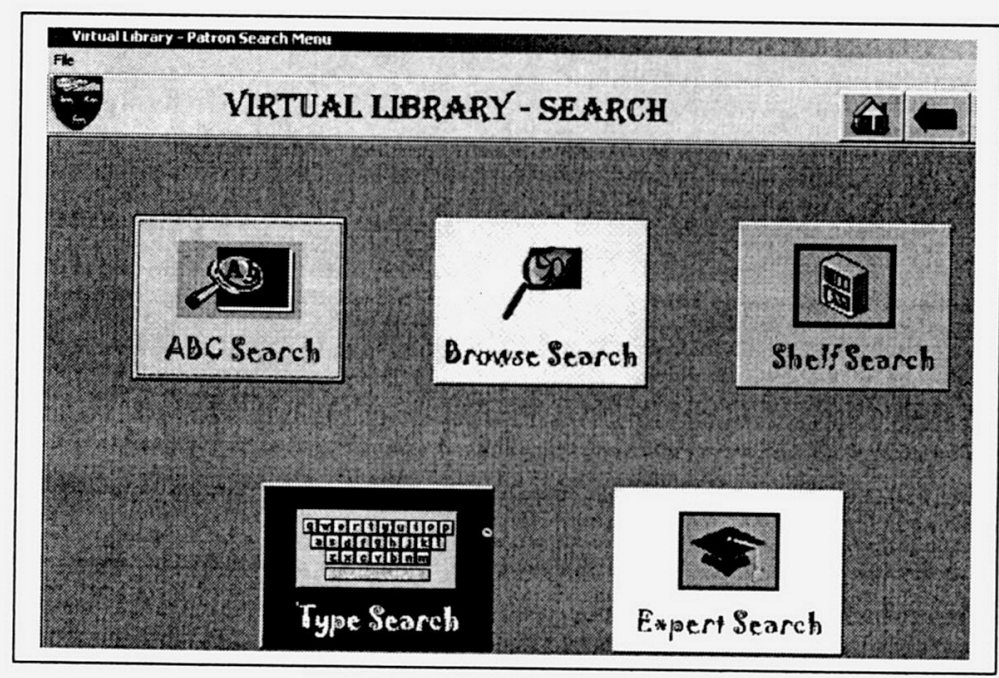




\section{ELIS - An Electronic Library Information System For Secondary Schools}

ELIS is a complete integrated library system and has the following functional requirements: Acquisition, Cataloguing, Circulation, Online Public Access Catalogue (OPAC), Bulletin \& Feedback, Maintenance and Reporting. The Administrator's module allows teacher librarians to access the entire system. Users can only access the OPAC and Bulletin \& Feedback. Figure 8 and 9 describe the provisions given under the Administrator and User Module

Figure 8: The Administrator's Functions Structure Chart

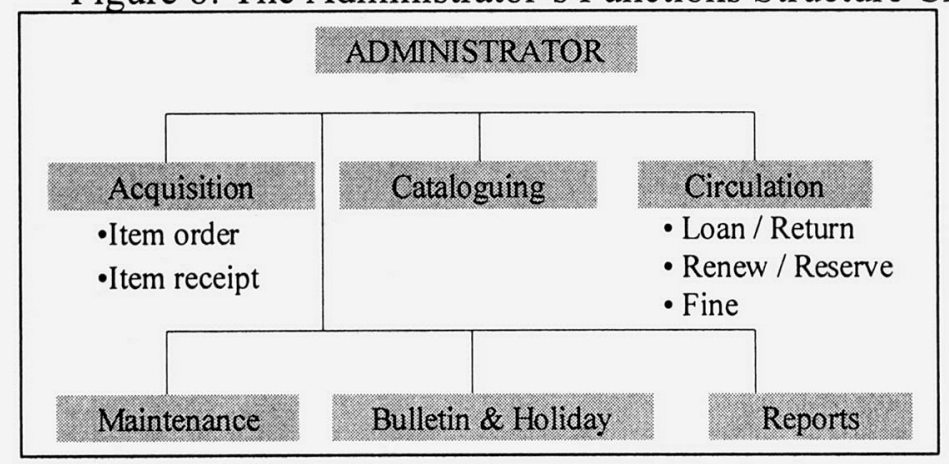

Figure 9: The Users Functions Structure Chart

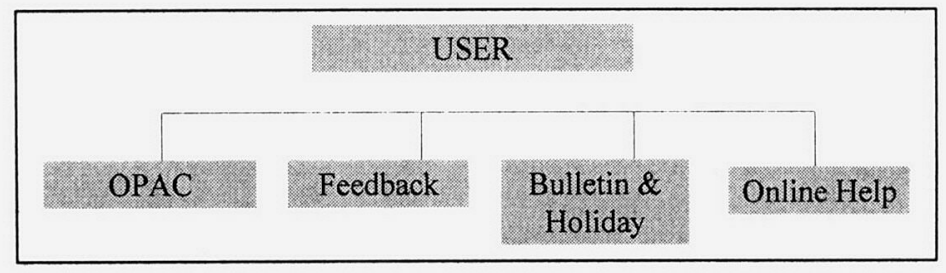

Figures 10 presents the main screen for ELIS. On a successful login, the initial ELIS window below will be shown.

Figure 10: Main Screen of ELIS

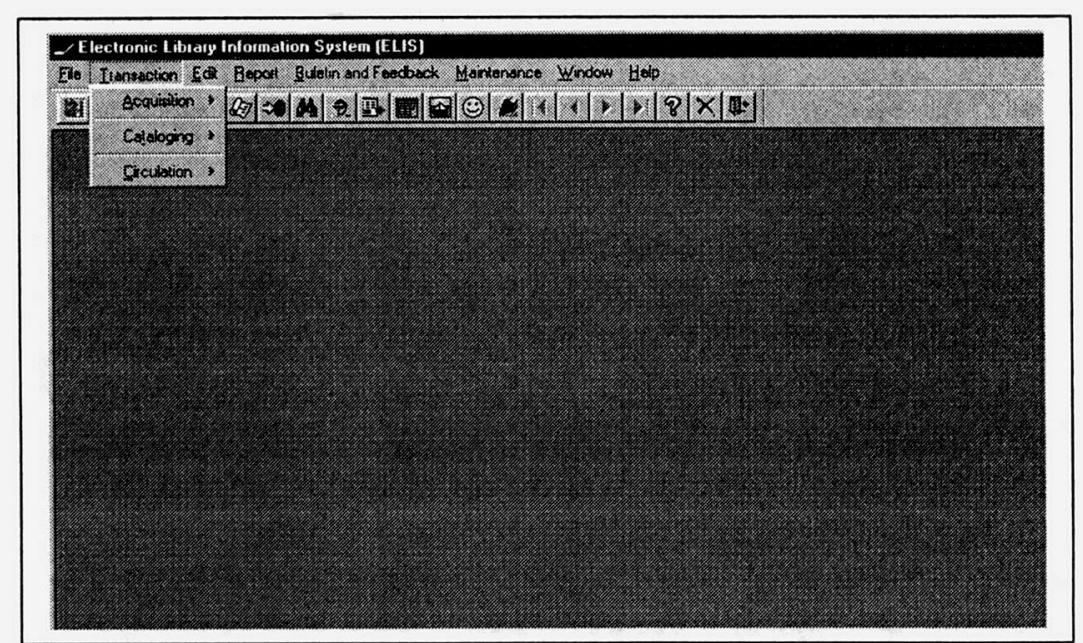


Figure 11 presents the user main screen for ELIS. Password is not required to access the User's Module.

\section{Figure 11: User Main Screen of ELIS}

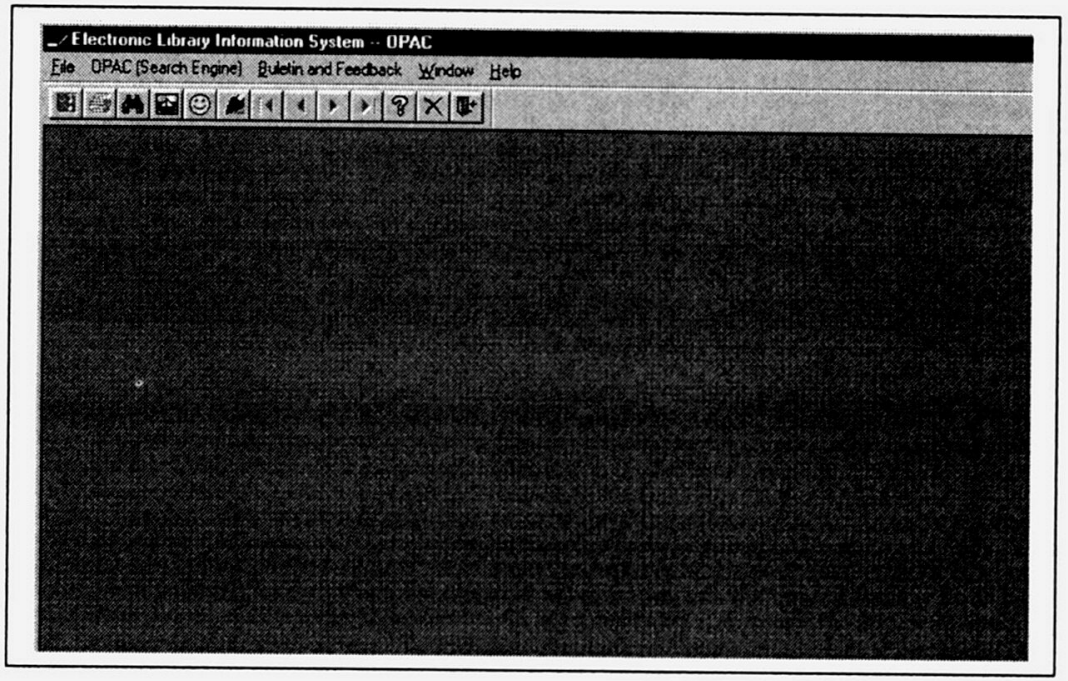

ELIS provides several search criteria suitable for both novice and expert users to search the library's catalogue - by Title, Author, Subject, Keyword in Title, Keyword in Author, Keyword in Subject and Keywords using Boolean. Figure 12 presents the Search Window with the available search criteria in a pull-down menu. To view a specific search result, users may double-click the saved search in the result set. ELIS's OPAC not only allows students to search the catalogue database in order to see if the library holds a particular item and to be informed of its location, but also informs users if the item is currently on loan, since the catalogue system is linked to the circulation system.

Figure 12: ELIS's OPAC

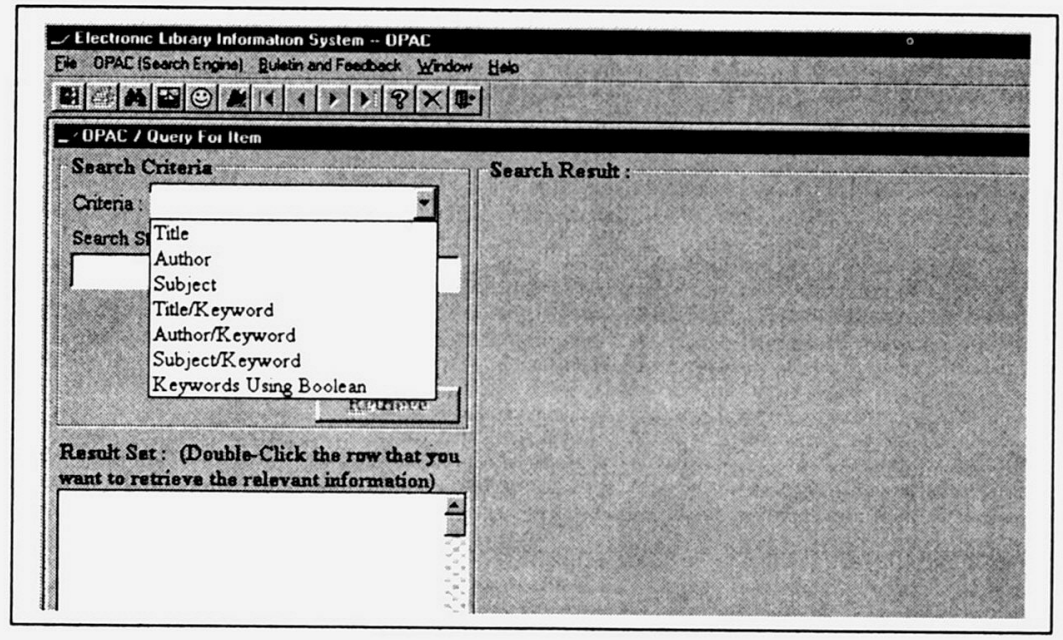

\section{User Testing}

Participating in the user acceptance test were 10 students who were non-randomly selected through a voluntary process. The participants were not involved in the initial survey. Each participant was interviewed with the researchers filling out the questionnaire based on the responses. A dummy database consisting of about 60 records were tested by 4 primary 
school students (for Virtual Library) and 6 secondary school students (for ELIS). Questionnaires only focused on the Search function for both systems.

In general, all participants found the system easy to use and they indicated they understand the language used for the system (English). Primary school students found Virtual Library's screen design to be attractive. All 4 children were successful in the search tasks given. They indicated preferring the Browse mode most. Secondary school students on the other hand had difficulties understanding some of the buttons and words used in ELIS, such as 'execute' and 'retrieve'. Two students indicated preference for Bahasa Melayu to English as the language of the system. However, none of the participants gave a negative rating to the systems.

\section{Conclusion}

Virtual Library and ELIS seem to be effectively used by students. As both systems are prototypes, they cannot be used as yet in real situations for a number of reasons. First they have not been tested with a larger set of sample bibliographic records. It is estimated that a database of about $2000-3000$ records need to be used to find out whether all modules continue to function smoothly.

Although Virtual Library and ELIS would be able to run smoothly, there is still much room for improvement on both. The possible future enhancements include the ability to support bar code scanner as the input device for data entry, the provision of interactive Help and the ability to convert the shelf list to MARC format.

Both systems are experiments in using a graphical-based library catalogue, which is an alternative to the commercially available online catalogues for school libraries. The experimental development of such a prototype is thought necessary to find out its usability by students and to form the basis of designing a working browser. It indicates the feasibility of using the systems, in the near future, for the information retrieval needs of students in Malaysian school libraries.

\section{Acknowledgements}

The authors would like to acknowledge Lee Hui Lan and Cheah Sooi Ping for developing Virtual Library and ELIS.

\section{References}

Al-Hawamdeh, Suliman. A new generation of library software. Paper presented at the AsiaPacific Library Conference, Brisbane, Australia, 28 May - 1 June 1995.

Borgman, C.L.; Hirsh, S.G.; Walter, V.A. and Gallagher, A.L. (1995). Children's searching behaviour on browsing and keyword online catalogues: The Science Library Catalogue Project. Journal of the American Society for Information Science, 46: 663684.

Clements, Douglas H. (1985). Computers in early and primary education. Englewood Cliffs, N.J.: Prentice Hall 
Drumm, John E and Groom, Frank. (1999). Teaching information skills to children. Computers in Libraries, vol. 19, no. 4: 48-51.

Edmonds, L.; Moore, P. and Balcom, K.M. (1990). The effectiveness of an online catalogue, Library Trends, 35: 647-667.

Hooten, P.A. (1989). Online catalogues: will they improve children's access? Journal of Youth Services in Libraries, 2: 266-272.

Moore, P.A. and St. George, A. (1991). Children as information seekers: the cognitive demands of books and library systems, School Library Media Quarterly, 19: 191-198.

Siegler, R.S. (1991). Children's thinking. $2^{\text {nd }}$ ed. Englewood Cliffs, N.J.: Prentice Hall. 